\title{
Residência Multiprofissional em Saúde e Serviço Social: dilemas na formação e trabalho profissional
}

\author{
Multiprofessional residency in health and social work: dilemmas \\ in formation and professional work
}

\section{Luciana da Conceição e Silva* Marcio Eduardo Brotto**}

\begin{abstract}
Resumo - Este artigo discutirá as contradições que abrangem o contexto de implementação do programa de Residência Multiprofissional em Saúde (RMS), no âmbito do Sistema Único de Saúde (SUS). O programa propõe formação para fortalecer o SUS, que vive uma realidade de precarização do trabalho e enfraquecimento de seus princípios universalizantes. Assim, compreende-se a inserção do Serviço Social na RMS como categoria importante por possuir potencial de fortalecimento da perspectivada Reforma Sanitária, bem como do seu Projeto Ético-Político Profissional, considerando sua relativa autonomia e tensões vivenciadas, advindas da relação entre intenção crítica versus condição de trabalhador assalariado. Daremos especial atenção à política de Saúde, uma vez que objetivamos apreender a construção da política de formação de recursos humanos dentro do SUS, problematizando os dilemas da formação, por meio do trabalho proposto pela RMS e sua estratégia de expansão no país.

Palavras-chave: residência; trabalho; Saúde; Serviço Social.
\end{abstract}

\begin{abstract}
This article will discuss the contradictions that comprise the context of implementation of the Multidisciplinary Residency Program in Health (RMS) in the Unified Health System (SUS).It offers training to reinforce the SUS, which experiences a reality of precarious work and weakening of its universalistic principles. The refore, it defends the inclusion of social services in the RMS as an important category for potentially strengthening the envisaged health reform, as well as the professional ethical-political project, considering its relative autonomy and the tensions experienced in the relation between critical intent in opposition to the condition of an employedlaborer. We will give special attention to health policy, as we aim to grasp the construction of the human resources training policy within the SUS and discuss the dilemmas arising in training through the work proposed by the RMS and its expansion strategy in Brazil.
\end{abstract}

\footnotetext{
* Assistente Social (UERJ). Especialista em Saúde da Mulher (UFRJ). Mestranda do Programa de Pós-graduação em Serviço Social da Pontifícia Universidade Católica do Rio de Janeiro (PUC-Rio). Correspondência: Rua Major Bezerra Cavalcanti, 296/ 209 - Centro. Rio Bonito -RJ. CEP: 28800-000. Email: <lucyesilva@hotmail.com>

** Assistente Social (UFRJ). Especialista em Serviço Social e Saúde (UERJ). Mestre e Doutor em Serviço Social (PUCRio). Docente do Programa de Pós-Graduação em Serviço Social da PUC-Rio e líder do Núcleo Integrado de Estudos e Pesquisas em Seguridade e Assistência Social.Correspondência: Rua Marques de São Vicente, 225 casa 209 - Vila dos Diretórios - Gávea - Rio de Janeiro.CEP: 22.451-900. Email: <meb.brotto@uol.com.br>
} 


\section{ApVistg all paUtg}

\} RESIDÊNCIA MULTIPROFISSIONAL EM SAÚDE - SILVA, L. C.; BROTTO, M. E. \}

DOI: $10.12957 /$ REP.2016.25396

\section{Introdução}

Neste artigo objetiva-se discutir a implementação do programa de Residência Multiprofissional em Saúde (RMS) ${ }^{1}$ no âmbito do Sistema Único de Saúde (SUS), bem como a inserção do Serviço Social, compreendido como uma importante categoria, protagonista do reforço para a perspectiva crítica da Reforma Sanitária na construção das RMS. No entanto, esse momento de implementação das residências em saúde, em suas diversas modalidades, esbarra em realidade avessa ao SUS e ao trabalho nesta área.

Partimos, assim, do pressuposto de que o contexto de implementação das RMS no país, diante das contrarreformas no SUS, é cercado pelo conflito entre os projetos em disputa na saúde. Da mesma forma, pressupomos que o Serviço Social - inserido nesse processo epermeado por tensões e disputas-é uma profissão com potencial crítico,capaz de contribuir para a formação, de acordo com o projeto sanitarista.

Daremos especial atenção à política de saúde, pois analisaremos a construção da política de formação de recursos humanos dentro do SUS, assim como os desafios e as possibilidades de fortalecimentodo perfil profissional voltado para o sistema, cujos princípios basilares são: cidadania, universalidade e integralidade. Fundamentais, estes princípios se contrapõem a uma realidade de desresponsabilização do dever do Estado(expressa no atendimento às demandas sociaiscom consequente perda de direitos do cidadão)e de crescente focalização e fragmentação das políticas.

Consideramos importante pesquisar os aspectos relacionados à formação e ao trabalho em saúde, na modalidade de residência, a fim de compreender seus limites e possibilidades para o fortalecimento do SUS, dentro de uma realidade que, em contradição ao modelo proposto por esse sistema, privatiza os serviços e focaliza as necessidades sociais da população. Nesse sentido, houve interesse em nos aproximar da particularidade da formação em saúde, nos moldes de Residência Multiprofissional.

A RMS é uma modalidade de formação com ênfase prática, desenvolvida em instituições que, apesar de sofrerem repercussões diretastanto da crise na saúde, quanto na educação-, são espaços potenciais para o ensino e a assistência em saúde,possuindo,como sujeito formador, os próprios profissionais que atuam nos serviços. Nesse contexto, cabem alguns questionamentos a respeito das iniciativas políticas do Ministério da Saúde (MS) para a formação de profissionais de saúde, tendo em vista o atual enfraquecimento da política de saúde, em contraposição ao princípio norteador da política de formação, que é o de fortalecer o SUS constitucional.

\footnotetext{
${ }^{1}$ Segundo a Resolução no 02 de 13 de abril de 2012, caracteriza-se como Residência Multiprofissional em Saúde o programa que for constituído por, no mínimo, três profissões da Saúde. A Resolução 287/98 do Conselho Nacional de Saúde lista 14 profissões consideradas da saúde essa área, dentre elas, o Serviço Social.
} 


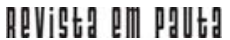

\} RESIDÊNCIA MULTIPROFISSIONAL EM SAÚDE - SILVA, L. C.; BROTTO, M. E.\}

DOI: $10.12957 /$ REP.2016.25396

No atual contexto de fragilização da seguridade social brasileira e da proposta constitucional de 1988, encontramos ações de resistência por parte de sujeitos que ocupam essas políticas. Nesse sentido, na saúde, além da materialidade legal, com os princípios que norteiam a própria política de saúde e que são totalmente avessos à concepção neoliberal, temos profissionais que trabalham no SUS e são considerados intelectuais potenciais; promotores de pensamentos, ações e proposições contra-hegemônicas à atual fase do capitalismo.

Assim, quando os profissionais estão envolvidos,tendo em vista as condições teóricas que dificultam a crítica da administração da coisa pública na sociedade capitalista, estes acabam tendo grande chance de reforçar as reformas neoliberais, contribuindo para fortalecer propostas de desmonte do Estado e de centralidade do mercado, como critério de organização da sociedade, ou seja, propostas que enfraquecem e desqualificam o SUS.

Pensando nisso, todas as modalidades de Residência em Saúde são especializações e devem pensar, criticar e propor sua correlação com o desenvolvimento do sistema de saúde em nosso país. Diante do enfrentamento de uma política de contrarreformas, a afirmação de um projeto profissional e político-pedagógico, voltado para uma formação crítica, reflexiva, teóricometodológica, técnico-operativa e ético-política, é de extrema importância à formação dos profissionais para o fortalecimento do SUS.

Consideramos que, no contexto avesso ao SUS universal e de qualidade, e como alternativa para resistir aos ditames do capital, é importante que se formem profissionais e/ou intelectuais críticos vinculados aos princípios e diretrizes do SUS, para que a relativa autonomia reservada aos profissionais de formação superior possa ser aproveitada a favor da luta pela saúde coletiva. Entendendo o protagonismo dos intelectuais/profissionais da saúde dentro da contradição da sociedade, nesta pesquisa, os preceptores (profissionais formadores) serão os sujeitos-chave para a análise das expressões de sua atuação junto aos residentes, como um modo de interrogar o objeto de estudo por meio dos sujeitos que dele participam.

Dentre as profissões envolvidas com a RMS, destaca-se a existência consolidada do Serviço Social, representando a terceira maior categoria em número de bolsas financiadas pelo Ministério da Saúde (BRASIL, 2006, p. 15). Neste artigo, pretendemos também nos aproximar do Serviço Social e das especificidades dessa categoria, na construção do seu atual Projeto Ético Político Profissional e dos desafios da materialidade na formação e exercício profissional. Compreendemos que a inserção do assistente social nas RMS se integra ao desafio de consolidação da formação e exercício crítico da profissão (o que, também, pode contribuir na formação de profissionais de outras áreas). 


\section{Perspectivas na política de Saúde: por que valorizar políticas de formação de profissionais dentro do próprio SUS?}

Os resultados da pesquisa de Vasconcelos $(2010)^{2}$ revelaram existir entre a maioria dos profissionais de saúde um desconhecimento sobre o SUS, bem como um reforçodo modelo privatizante na saúde e um afastamento dos espaços de controle social. Tendo em vista que estes profissionais, além de atuarem no sistema, estão formando outros profissionais,a tendência é que o que vem se reproduzindo seja um perfil profissional que desconhece a relevância do SUS e seus espaços políticos. Dessa forma, esses profissionais podem não se mostrar engajados na defesa da universalidade e da integralidade em saúde, não sendo capazes de democratizar, junto aos usuários, informações para além dos aspectos clínicos e biomédicos. Assim, segundo a pesquisa desenvolvida pela referida autora, há uma fragilidade na formação de profissionais que saibam fazer saúde coletiva de proteção e promoção. Entretanto, a mesma pesquisa destaca uma particularidade na formação dos assistentes sociais que pode influenciar no exercício profissional.

Segundo os dados parciais da pesquisa, ao analisar a concepção de saúde dos profissionais, observou-se que a maioria das categorias e demais profissionais optam pelo conceito da Organização Mundial de Saúde, enquanto que a maioria dos assistentes sociais referencia sua prática com o conceito de saúdedo projeto da Reforma Sanitária ${ }^{3}$. Os dados mostram que a concepção de saúde abstrata da OMS continua orientando a prática de muitas profissões, em detrimento da discussão sobre os determinantes sociais e econômicos da saúde. Excetuando a categoria dos assistentes sociais, verificamos que a maioria dos demais profissionais tomam como diretriz o conceito de saúde ampliada, com base na Constituição Federal de 1988.

Seguindo a mesma perspectiva, constatou-se, na pesquisa de Vasconcelos (2010), que 45\% dos profissionais de outras categorias afirmam desconhecer a contribuição do Movimento de Reforma Sanitária. Isso significa, por conseguinte, que quase metade do total de entrevistados não reconhecem a importância deste movimento para a Saúde brasileira, ao passo que entre a categoria dos assistentes sociais todos reconhecem o Movimento de Reforma Sanitária como fundamental para a questão de saúde no Brasil.

\footnotetext{
${ }^{2}$ A pesquisa "A prática dos profissionais de Saúde no município do Rio de Janeiro: HU's". Pesquisa foi realizada com 349 profissionais de Saúde dos hospitais da Universidade Federal do Rio de Janeiro (UFRJ) e da Universidade do Estado do Rio de Janeiro (Uerj). Foram entrevistados assistentes sociais, enfermeiros, farmacêuticos, fisioterapeutas, fonoaudiólogos, médicos, nutricionistas, psicólogos e terapeutas ocupacionais.

${ }^{3}$ O movimento da Reforma Sanitária nasceu no contexto da luta contra a Ditadura, no início da década de 1970. A expressão foi usada para se referir ao conjunto de ideias que se tinha em relação às mudanças necessárias na área da Saúde em busca da melhoria das condições de vida da população. As propostas da Reforma Sanitária resultaram na criação do Sistema Único de Saúde (SỦS).
} 


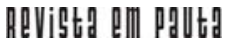

\} RESIDÊNCIA MULTIPROFISSIONAL EM SAÚDE - SILVA, L. C.; BROTTO, M. E. \}

DOI: $10.12957 /$ REP.2016.25396

Em estudo ${ }^{4}$ realizado no âmbito do Núcleo de Estudo, Extensão e Pesquisa em Serviço Social (Neeps/Uerj) ${ }^{5}$, nota-se que a fratura que ocorre entre o exercício profissional e as possibilidades de prática crítica existentes na realidade relaciona-se tanto com o ensino das profissões de Saúde (já que em suas diretrizes curriculares há um esvaziamento de conteúdos essenciais para um projeto de profissão), quanto pela necessidade de ampliação e fortalecimento da discussão sobre políticas públicas de Saúde. A partir disso, observou-se ocorrer um discurso de louvação do SUS, que não altera a lógica do ensino e as diretrizes curriculares das profissões de Saúde. Essas diretrizes, por sua vez, não tendem a fortalecer o projeto de Reforma Sanitária,mas se resumem a apontar conteúdos genéricos, focalizadores, gerando uma fragmentação do ensino (AGUIARet al, 2008).

Nessa lógica, este processodeixa de garantir conteúdos mínimos referentes a políticas sociais públicas de Saúde, capazes de garantir um perfil profissional crítico, formador de intelectuais e não apenas de técnicos. Dessa forma, a diversidade da formação em Saúde pode demonstrar as possibilidades e os limites dos profissionais para a realização de ações que levem em conta, antes de tudo, os princípios socializantes do SUS e as reais necessidades sociais de Saúde da população.

A partir dos dados e reflexões do relatório da Conferência Nacional de Recursos Humanos de 1993, assim como das diretrizes apresentadas pela Norma Operacional Básica de Recursos Humanos para o Sistema Único de Saúde (NOB/RH-SUS), verificou-se que o perfil dos profissionais formados não é adequado o suficiente para uma atuação na perspectiva da atenção integral à Saúde e de práticas que contemplem ações de promoção, proteção, prevenção, atenção precoce, cura e reabilitação.

Uma das estratégias para o enfrentamento dessa constatação foi implantação de cursos de especialização na área de Saúde, direcionados ao fortalecimento de políticas públicas;prática habitualmente utilizada pelo Ministério da Saúde. Nessa mesma linha, os cursos de especialização e RMS foram concebidos para dar suporte teórico-prático aos profissionais, já inseridos nas equipes, e oferecer, em especial aos recém-egressos, uma formação mais voltada às necessidades do SUS.

Nessa conjuntura, os programas de RMS foram pensados com o objetivo de contribuir para a revisão do modelo assistencial, na medida em que podem formar um novo perfil do profissional de Saúde, preparado para responder às reais necessidades de Saúde dos usuários, tendo em vista a atual centralidade da expansão da atenção básica, a partir do modelo assistencial da Estratégia Saúde da Família (ESF) no país. Essa realidade demanda a formação de um perfil profissional diferente do que tem sido

${ }^{4}$ Estudo a respeito das diretrizes curriculares dos cursos de profissões de Saúde e sua relação com a formação e prática profissional, publicado nos anais do Encontro de Pesquisadores de Serviço Social 2008 (ENPESS, 2008).

${ }^{5} \mathrm{O}$ Núcleo de Estudo, Extensão e Pesquisa em Serviço Social (Neepss) está inserido na Faculdade de Serviço Social da Universidade do Estado do Rio de Janeiro (FSS/Uerj). 


\section{ApVistg all paUtg}

\} RESIDÊNCIA MULTIPROFISSIONAL EM SAÚDE - SILVA, L. C.; BROTTO, M. E. \}

DOI: $10.12957 /$ REP.2016.25396

apresentado pelas graduações, geralmente muito especializadas. Diante desse fato, há uma preocupação em investir na formação de profissionais que estejam capacitados a intervir de forma multiprofissional.

O processo de aprendizado na RMS, caracterizado pela formação por meio do trabalho nos serviços, ocorre dentro de um contexto complexo de interações e relações entre preceptores ${ }^{6}$, coordenadores, tutores, residentes ${ }^{7}$ e demais profissionais de diferentes áreas do conhecimento, usuários dos serviços e das instituições.

É válido ressaltar que a Reforma Sanitária Brasileirainfluenciou a 8ํㅡㄹerência Nacional de Saúde (1986), a Assembleia Nacional Constituinte (1988), as Leis Orgânicas da Saúde (Lei Federal nº 8.080/90e 8.142/ 90) e a Norma Operacional Básica de Recursos Humanos para o Sistema Único de Saúde - NOB/RH-SUS (BRASIL, 2005). Tais normas e eventos instituíram a necessidade de mudanças nos modelos de atenção à Saúde e à transformação nos processos formativos de profissionais desta área (BRASIL, 2006).

Diante desse contexto, "novos perfis profissionais foram solicitados, colocando em pauta as tensões entre SUS e a formação dos trabalhadores" (LOBATO, 2010, p. 33). Porém, para que os profissionais da Saúde "sejam, na assistência, no ensino ou na gestão, sujeitos instituintes de mudança nas práticas do mundo do trabalho e se constituam em contra hegemonia ao instituído, outras estratégias e referenciais devem ser consideradas" (LOBATO, 2010, p. 33). Para tanto, a proposta da RMS tem tido ênfase e expansão por propor, como basilar, a educação no mundo do trabalho e para o trabalho.

Neste cenário, a Educação Permanente em Saúde (EPS) ${ }^{8}$, enquanto política, propõe-se a colocar o SUS como interlocutor na formulação dos projetos político-pedagógicos de formação dos trabalhadores, com a finalidade de proporcionar práticas condizentes com os princípios do SUS. Para tal, é preciso cada vez mais investir na perspectiva de que não seja apenas considerado como um campo de práticas (BRASIL, 2004), assim como reforçar a necessidade de que os projetos das instituições formadoras considerem as diretrizes que orientam a criação do sistema, a saber: descentralização, universalidade, integralidade e participação social (BRASIL, 2005).

\footnotetext{
${ }^{6}$ Segundo a Resolução CNRMS no 2 de 13 de abril de 2012, tutor é o profissional cuja função caracteriza-se por atividade de orientação acadêmica de preceptores e residentes. Preceptor é o profissional cuja função caracterizase por supervisão direta das atividades práticas realizadas pelos residentes nos serviços de saúde. Tal resolução ainda traz definição dastutorias, bem como dos docentesdas RMS (BRASIL, 2012).

${ }^{7}$ Interessante salientar que nos documentos oficiais não há definição de quem é o residente multiprofissional em saúde. Portanto, explicitamos que estes são profissionais formados em áreas de saúde não médicas que se inseridos nos programas de residência como discentes do curso.

${ }^{8}$ Educação Permanente em saúde significa a produção de conhecimentos no cotidiano das instituições de saúde, a partir da realidade vivida pelos sujeitos envolvidos, tendo os problemas enfrentados no dia a dia do trabalho e as experiências desses sujeitos como base de interrogação e mudança (CECCIM e FERLA, 2005).
} 
Cecccim e Feuerwerker, (2004) já levantavam o problema de que a formação dos profissionais de Saúde permanecia alheia ao debate crítico sobre os sistemas de organização do cuidado, defendendo que as instâncias do SUS deveriam cumprir papel indutor da mudança, tanto do trabalho quanto da formação profissional. Os autores aindapropunham o trabalho articulado entre o sistema de Saúde e as instituições formadoras, que não podem existir sem a regulação pública e da direção política do SUS, sugerindo, dessa forma, a educação em serviço:

a educação em serviço é uma proposta apropriada para trabalhar a construção desse modo de operar o sistema, pois permite articular gestão, atenção, ensino e controle social no enfrentamento dos problemas concretos de cada equipe de Saúde em seu território geopolítico de atuação (CECCCIM; FEUERWERKER, 2004, p. 51).

Nesse cenário, portanto, uma das políticas desenvolvidas pela Secretaria de Gestão do Trabalho e da Educação da Saúde (SGTES/MS) é de fomento das RMS, com o objetivo de ser uma pós-graduação para formar profissionais nos hospitais universitários federais, hospitais de ensino, instituições de ensino superior e secretarias estaduais e municipais de Saúde, todos em campos de atuação estratégicos para SUS e em regiões prioritárias do país.

\section{Residência Multiprofissional em Saúde: afinal, de que se trata? Disputas entre o projeto sanitário e o projeto privatista}

O Ministério da Saúde vem apoiando as RMS, desde 2002, por meio do estabelecimento de financiamento regular para os programas desta modalidade no Brasil. Segundo o MS, o investimento na sua potencialidade pedagógica e política tem por objetivo possibilitar a formação de profissionais, quanto contribuir com a mudança do desenho técnico-assistencial do SUS. Demonstra, dessa forma, a centralidade da formação para o trabalho em Saúde que, no caso das residências, torna-se um espaço privilegiado por se tratar de uma formação no e pelo trabalho.

$\mathrm{Na}$ perspectiva de criar uma política de valorização do trabaIhador do SUS e de cumprir o art. 200 da Constituição Federal, foi criada a Secretaria de Gestão do Trabalho e da Educação na Saúde (SGTES) (BRASIL, 2009). Assim, o Departamento de Gestão da Educação, em 2003, começa a desenvolver suas ações pautadas na Política Nacional de Formação e Desenvolvimento para o SUS: Caminhos para a Educação Permanente em Saúde, aprovada pelo Conselho Nacional de Saúde (CNS), no mesmo ano (BRASIL, 2009).

Esse contexto possibilitou a viabilização da Comissão de Residências em Saúde e, por conseguinte, a criação da Comissão Nacional de Residência Multiprofissional (CNRM). Diante disso, é instituída a Lei nº 11.129 


\section{ADVistg all paUtg}

\} RESIDÊNCIA MULTIPROFISSIONAL EM SAÚDE - SILVA, L. C.; BROTTO, M. E.

DOI: $10.12957 /$ REP.2016.25396

de 30 de junho de 2005, que estabelece acriação da Residência em Área Profissional da Saúde, excetuada a área médica. Porém, é a Portaria Interministerial MEC/MS no 2.117 que institui a RMS, estimulando vários grupos a se articularem, em diversas regiões do país, para construir novos programas de residência nesta modalidade (BRASIL, 2006).

Em seus princípios norteadores, a RMS aborda a Educação Permanenteem Saúde como eixo pedagógico estruturante dos programas, considerando-o como sendo um espaço para o seu desenvolvimento, e como dispositivo potencial para promover mudança dos modelos de gestão e atenção do SUS (BRASIL, 2006). A RMS constitui-se como uma modalidade de formação pós-graduada (lato sensu), que se realiza pela prática profissional responsável, por propor processos formativos enraizados na humanização, no acolhimento, na participação do usuário, na ação multiprofissional integral e na qualidade dos serviços de Saúde, consolidando, assim, os princípios que norteiam o SUS (LOBATO, 2010).

Hoje, a RMS se encontraatrelada a um contexto de grandes disputas, lutas políticas e sociais, exigindo que os sujeitos envolvidos assumam posição de protagonistas deste processo (LOBATO, 2010). Além disso, requer contribuições para a formação de sujeitos com a capacidade de compreender e significar, de modo ampliado, os desafios de implementação do SUS e as necessidades individuais e coletivas de uma determinada população. Da mesma forma, demarca a necessidade de habilidades, conhecimentos e atitudes para elaboração, execução e coordenação de intervenções produtoras de autonomia, apropriados de uma pedagogia que os permitam ser sujeitos da construção de saberes de modo permanente (RAMOS et al., 2006, p.379).

Segundo o discurso oficial desta modalidade de ensino pelo trabalho, a RMSse constitui como uma das estratégias potenciais para repensar o processo de formação em Saúde (BRASIL, 2006). Busca-se, dessa maneira, proporcionar uma nova perspectiva teórico-pedagógica convergente com os princípios e diretrizes do SUS, promovendo, além do contato entre o mundo do trabalho e o mundo da formação, o desenvolvimento de mudanças de modelo tecnoassistencial, em vista às necessidades regionais (BRASIL, 2006).

Nessa defesa, no campo da Saúde, a educação pelo trabalho é considerada uma possibilidade para o desenvolvimento de novos perfis profissionais que visem à integralidade da atenção, princípio que norteia o SUS (CECCIM; FERLA, 2009). Além disso, a presença permanente nos locais de "produção de ações e o estabelecimento de estratégias de aprendizagem coletiva, em equipe multiprofissional, podem ser eficientes na formação dos trabalhadores para a integralidade" (LOBATO, 2010, p. 33).

Assim, a RMS afirma ter como objetivo a formação de profissionais para uma atuação diferenciada no SUS, constituída como estratégia de mudança da formação dos trabalhadores da Saúde, com construção interdisciplinar, trabalho em equipe educação permanente, portanto, de reo- 


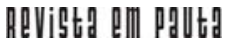

\} RESIDÊNCIA MULTIPROFISSIONAL EM SAÚDE - SILVA, L. C.; BROTTO, M. E.\}

DOI: $10.12957 /$ REP.2016.25396

rientação das lógicas assistenciais (LOBATO, 2010). O que se agrega a esta nova modalidade de formação resulta em ações educativas centradas nas necessidades de Saúde da população, na equipe multiprofissional e numa possibilidade de maior institucionalização da Reforma Sanitária Brasileira, que vem ao encontro do que preconiza os princípios do SUS.

Interessa-nos saber se, na tentativa de efetivação do SUS, a indução de políticas públicas, com interferência direta no modelo educacional, contribuirá para o aprimoramento da formação profissional, na perspectiva da educação permanente, ou se é mais uma estratégia de estruturar a rede de Saúde através da oferta de um campo de trabalho precarizado para os profissionais de Saúde.

O Ministério da Saúde objetivando intervir no modelo de formação e no trabalho em Saúde se propôs a lançar programas que visam construir um trabalho interdisciplinar e coletivo, atento aos princípios e diretrizes do SUS. Dessa forma, possibilita um trabalho com potencial de entrosamento das categorias profissionais de Saúde de formação superior: Serviço Social, Enfermagem, Farmácia, Odontologia, Veterinária, Química, Psicologia, Nutrição, Fisioterapia, Terapia Ocupacional, Biologia, Biomedicina, Fonoaudiologia (BRASIL,1998).

Dentre os programas, destacam-se: a) Pró-Saúde: Programa Nacional de Reorientação da Formação Profissional em Saúde, que tem por objetivo a integração ensino-serviço. Dá ênfase à Atenção Básica, visando à promoção de transformações na prestação de serviços à população; b) PET-Saúde: Programa de Educação pelo Trabalho para a Saúde. Tem como fio condutor a integração ensino-serviço-comunidade e visa fomentar a formação de grupos de aprendizagem tutorial em áreas estratégicas para o SUS. Caracteriza-se como instrumento para qualificação em serviço dos profissionais da Saúde e formação dirigida aos estudantes das graduações em Saúde; c) Programas de Residência em Saúde, que visa o aperfeiçoamento de profissionais já graduados em áreas de saúde para a assistência à Saúde da população brasileira e para a reorganização do processo de trabalho em Saúde buscando fortalecer o SUS.

Verifica-se que, na implementação desses programas, o discurso oficial é de que se busca a construção de uma nova consciência sanitária e pedagógica, além da formação do trabalho coletivo, com base na interdisciplinaridade. Vale destacar que um forte componente dessa indução é o financiamento do MS para as instituições e secretarias estaduais de Saúde, as quais são contempladas com fornecimento de bolsas para alunos, preceptores e tutores. Tal financiamento está direcionado ao desenvolvimento de atividades de ensino, pesquisa e extensão na área da atenção primária em Saúde. Mesmo antes dessas iniciativas, o MS reconhecia a necessidade de ampliar, para além da medicina, a formação na modalidade residência.

Em relação às RMS, suas características são: formação em serviço, supervisão direta por profissionais capacitados (preceptoria), supervisão 


\section{ADVistg all paUtg}

\} RESIDÊNCIA MULTIPROFISSIONAL EM SAÚDE - SILVA, L. C.; BROTTO, M. E. \}

DOI: $10.12957 /$ REP.2016.25396

acadêmica (tutoria), regime de dedicação exclusiva, cenários de formação e práticas em serviços da rede de atenção à Saúde, nos três níveis de complexidade. Nas residências, as atividades de formação têm por objetivo desenvolver habilidades e competências para os profissionais atuarem em determinadas situações locais de Saúde.

Porém, a análise dessa proposta de estruturação e mudança do trabalho em Saúde, através do investimento nessa modalidade de ensino, não pode ser pautada apenas pelo discurso oficial. Nesse sentido, indagamos o porquê de, ao invés de haver investimento na qualidade dos serviços de Saúde para que assim o perfil profissional possa se adequar ao processo de trabalho condizente com as propostas do SUS -, a política de formação vem focando na expansão de vagas para especializações através do trabalho. Estas possuem carga-horária elevada (exigindo dedicação exclusiva) e salário (bolsa) abaixo do piso normal de um profissional de Saúde (apesar da bolsa das residências serem maiores que muitos salários pagos a profissionais de Saúde, tanto em algumas empresas privadas, quanto em muitos concursos públicos). Além disso, convém destacar que a carga-horária do residente é de 60 horas semanais.

Dessa forma, apesar dos esforços do movimento sanitário para uma formação em Saúde articulada aos princípios do SUS, a atual proposta de residência em Saúde, em tempos neoliberais, pode fortalecer ainda mais a lógica do mercado nas políticas de Saúde. O fortalecimento do mercado pode ser observado na influência neoliberal, tanto pela substituição deprofissionais estáveis e vinculados aos serviços por força de trabalho mais barata, temporária e precarizada; quanto pelatentativa de "interiorizar" e expandir ações de Saúde no país sob a lógica de inserção de residentes em áreas com a atenção mal estruturada, sem garantias de articulação de espaços e profissionais formadores para tutoria, supervisão e docência o que compromete, além da qualidade da expansão desses serviços, a própria formação dos profissionais.

Segundo Behring e Boschetti (2006), apesar das lutas democráticas e dos movimentos sociais que levaram inclusive às conquistas em 1988, os anos de 1990 foram marcados pela contrarreforma do Estado e, atualmente, essa tendência vem se agravando. A reforma, segundo as autoras, pode ser considerada como um patrimônio da esquerda e das conquistas geradas pela luta dos trabalhadores. Contudo, com o neoliberalismo, as políticas sociais entraram num ambiente contrarreformista, com medidas orientadas para o mercado.

Segundo Bravo(2009), com relação à Saúde, havia expectativa de que os governos do Partido dos Trabalhadores (PT) fortalecessem o projeto de Reforma Sanitária construído nos anos 1980 e que foi questionado na década de 1990, havendo, no período, a consolidação do projeto de Saúde articulado ao mercado privatista. O atual governo, entretanto, apesar de explicitar como desafio a incorporação da agenda ético-política da re- 


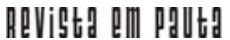

\} RESIDÊNCIA MULTIPROFISSIONAL EM SAÚDE - SILVA, L. C.; BROTTO, M. E.\}

DOI: $10.12957 /$ REP.2016.25396

forma sanitária, pelas suas ações tem mantido a polarização entre os dois projetos (Reforma Sanitária versusprojeto privatista). Em algumas proposições, procura fortalecer o primeiro projeto e, na maioria de suas ações, mantém o segundo quando as ações enfatizam a focalização e a precarização dos recursos humanos, em decorrência do desfinanciamento.

A focalização pode ser identificada pela centralidade do Programa Saúde da Família (PSF), sem alterá-lo significativamente para que se transforme em estratégia de (re)organização da atenção básica, em vez de ser um programa de extensão de cobertura para as populações pobres. Nessa direção, precisa prover a atenção básica em Saúde para toda a população, tendo por objetivo a (re)organização do sistema e a articulação com os demais níveis de assistência (média e alta complexidade), de acordo com os princípios da integralidade e universalidade do SUS.

A precarização e terceirização dos recursos humanos evidenciamse a partir da ampliação da contratação de agentes comunitários de Saúde e inserção de outras categorias que não são regulamentadas: auxiliar e técnico de saneamento, agente de vigilância sanitária, e agentes de Saúde mental. A incorporação dos agentes comunitários de Saúde na equipe do PSF já foi polêmica, gerando diversos debates centrados na ausência de regulamentação da profissão, como também acerca da imprecisão de suas funções, da precarização das contratações e da falta de concurso público para a seleção dos profissionais o que tem se realizado, na maioria dos casos, com base em indicações político-partidárias (BRAVO, 2009).

No que se refere às novas formas de gestão do trabalho na Saúde e sua privatização, há, ainda, a criação de novas organizações não estatais, tais como as "Fundações Estatais de Direito Privado", "Organizações Sociais" e "Organização da Sociedade Civil de Interesse Público", que, por mais que exerçam funções de caráter público, obedecem às leis do mercado. Resultam, assim, na precarização das relações de trabalho no âmbito da Saúde. Por isso, essa precarização se reflete na falta de reajuste salarial e, principalmente, nas diversas formas de contrato (através das fundações ou cooperativas) que, muitas vezes, são temporários e sem garantias trabalhistas o que inviabiliza a construção e continuidade de um projeto de atuação e participação em formação (BRAVO, 2006).

A questão do desfinanciamento é a mais séria, pois está diretamente articulada ao gasto social do governo e é a determinante para a manutenção da política focal, de precarização e terceirização dos recursos humanos. O financiamento da Saúde tem geradograves problemas, tais como a utilização sistemática dos recursos do orçamento da Seguridade Social para garantir o superávit primário das contas públicas. Outro aspecto central é a desvinculação de receitas da União (DRU), com a utilização dos recursos arrecadados de impostos e contribuições sociais para pagamento da dívida pública (BRAVO, 2009).

Segundo Mendes (2013), os dados da Organização Mundial da Saúde (2013) sobre o financiamento dos sistemas de saúde mostram que o 


\section{ApVistg all paUtg}

\} RESIDÊNCIA MULTIPROFISSIONAL EM SAÚDE - SILVA, L. C.; BROTTO, M. E. \}

DOI: $10.12957 /$ REP.2016.25396

Brasil gasta, em Saúde, 9\% do Produto Interno Bruto (PIB). Esse valor indica que o Brasil tem um gasto total em Saúde pouco abaixo do registrado em países desenvolvidos, contudo, quando se examina o percentual do gasto público em Saúde, verifica-se que ele é muito baixo e incapaz de garantir que a norma constitucional se materialize na prática social, de modo a assegurar o princípio da universalidade do SUS. Neste contexto, as evidências internacionais mostram que todos os países que organizaram sistemas universais de Saúde apresentam uma estrutura de financiamento em que os gastos públicos em Saúde são, no mínimo, 70\% dos gastos totais.

No Brasil, o gasto público como percentual do gasto total em Saúde é de apenas $47 \%$, inferior aos $53 \%$ que constituem o percentual de gastos privados em Saúde (via incentivos fiscais, desconto no imposto de renda de despesas com Saúde e isenção de impostos de serviços classificados como filantrópicos). Sendo assim, com a realidade de subfinanciamento na estrutura vigente de gastos públicos em Saúde, não se pode pretender consolidar o SUS como direito de todos e dever do Estado.

O Brasil, sendo a sétima economia do mundo, é o $72^{\circ}$ em investimento em Saúde (MENDES, 2013).Desde meados da década de 1960, o Estado brasileiro estimula o setor privado em Saúde via incentivos fiscais. Parte desse incentivo se deu com objetivo de utilizar os serviços de uma rede já instalada, mas sua intensificação tem a ver com o financiamento de campanhas para os legislativos e executivos. O poder de lobby das empresas de Saúde tem se acentuado e a representação no parlamento de defensores do SUS tem diminuído (BRAVO et al., 2015).

Em tempos de crise, há algumas iniciativas claras de desmantelamento do que existe, como, por exemplo, por parte do Governo Federal: a PEC 86, que estabelece que os percentuais mínimos para investimento em Saúde devem ser calculados não mais sobre a receita bruta do Estado, mas sobre a receita corrente líquida; a "Agenda Brasil", proposta pelo Senador Renan Calheiros, que em seu texto original orientava "avaliar possibilidade de cobrança diferenciada de procedimentos do SUS por faixa de renda"; além destas, também a proposta do deputado Eduardo Cunha, a PEC 451, que "inclui como garantia fundamental, plano de assistência à Saúde, oferecido pelo empregador em decorrência de vínculo empregatício, na utilização dos serviços de assistência médica"; a aprovação pela Câmara de Medida Provisória, que visava anistiar dívidas bilionárias de multas das empresas de medicinade grupo (vetada pela presidente Dilma). Como podemos notar, são diversas as evidências de que existem iniciativas institucionais de favorecimento do setor privado, ao custo do desmantelamento do SUS (CISLAGHI, 2015b). ${ }^{9}$

${ }^{9}$ Cruzamento de dados feito pelo projeto Faces de Cunha, do site Brasil de Fato, mostra que a Bradesco Saúde está entre as cinco empresas que mais financiaram a campanha de 214 deputados da atual legislatura. Foram mais de $\mathrm{R} \$$ 4 milhões distribuídos entre 11 partidos, sendo que metade deste valor foi para o PSDB (R\$1,2 milhão) e PMDB (R\$ 820,9 mil). À campanha de Eduardo Cunha (PMDB-RJ) tal empresa doou R\$ 250 mil. 


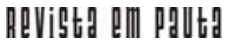

\} RESIDÊNCIA MULTIPROFISSIONAL EM SAÚDE - SILVA, L. C.; BROTTO, M. E. \}

DOI: $10.12957 /$ REP.2016.25396

Dessa forma, no que se refere às residências em Saúde, interessanos refletir se, na tentativa de efetivação do SUS em tempos de hegemonia neoliberal, a indução de políticas públicas, com interferência direta no modelo de ensino/trabalho educacional, vai contribuir e fortalecer a formação e o trabalho profissional, na perspectiva da Reforma Sanitária, ou se pode fortalecer a estratégia de estruturar a rede de Saúde, através da oferta de um campo de trabalho precarizado para os profissionais de Saúde. Além disso, nota-se que, nessa estratégia de formação pelo trabalho, o governo estabelece uma forma de contrato aviltante, temporário e precário para os residentes, no qual exclui do trabalhador o direito a férias e licença remunerada bem como o $13^{\circ}$ salário, FGTS, adicional de insalubridade e estabilidade. Além disso, obriga os bolsistas a pagarem o INSS como contribuintes individuais, sem que haja contribuição patronal, ao invés de instituir um plano de carreira para os profissionais da Saúde, o que consequentemente fortaleceria, de fato, o SUS.

Soma-se a isso a precarização dos serviços de Saúde em si, submetendo os profissionais, já inseridos no SUS, à dinâmica contrária aos princípios sanitários do sistema de Saúde. Isso ocorre tendo em vista a fragmentação da seguridade social, a real precarização de implementações dos cursos de residência pelo país e a falta de integralidade dos serviços o que compromete a realização de um trabalho multiprofissional e intersetorial. Agregada a essas questões está a crescente privatização dos equipamentos e da gestão do trabalho em Saúde.

Santos (2012) defende que, no caso brasileiro, entre as particularidades da "questão social"10 está, de um lado,a superexploração do trabalho e, de outro, uma passivização das lutas sociais que historicamente foram mantidas sob controle do Estado e das classes dominantes. Segundo a autora, a "flexibilização/precariedade" do trabalho no Brasil não pode ser creditada somente à crise recente do capitalismo, pois faz parte da nossa característica de exploração do trabalho.

A manutenção de um fluxo permanente de demissões e contratações, ou seja, de uma política de substituição dos trabalhadores que não conseguem, na sua maioria, ultrapassar os anos iniciais da carreira, reduz os custos de seleção, além de reduzir os custos trabalhistas.

O atual quadro das políticas sociais aprofunda a precarização do padrão de proteção social por meio da centralidade da assistência social focalista e a passivização dos trabalhadores e movimentos sociais. É fato que: se aumenta o grau de precarização e flexibilidade do trabalho, aumenta, na mesma proporção, sua exploração. Sabe-se da funcionalidade que os processos de precarização e contratação possuem como fonte de "bara-

\footnotetext{
${ }^{10} \mathrm{~A}$ questão social é expressão da contradição fundamental do modo capitalista de produção. Contradição esta fundada na apropriação privada da riqueza produzida coletivamente. Neste terreno contraditório entre a lógica do capital e a lógica do trabalho, a questão social representa não só as desigualdades, mas, também, o processo de resistência e luta dos trabalhadores (SANTOS, 2012).
} 


\section{ReVistg all pavtg}

\} RESIDÊNCIA MULTIPROFISSIONAL EM SAÚDE - SILVA, L. C.; BROTTO, M. E. \}

DOI: $10.12957 /$ REP.2016.25396

teamento" do valor trabalho e como sua utilização tem sido cada vez mais recorrente, em diversos setores do mundo do trabalho, inclusive nos Recursos Humanos da Saúde.

Além da precarização da política de Saúde e do trabalho no SUS, observa-se a dificuldade que esses profissionais, inseridos como formadores, têm de apreender a perspectiva de crítica da Reforma Sanitária e organizar o serviço no modelo multiprofissional e de participação social, como demanda o SUS. Tais dificuldades nos fazem indagar como seria para estes profissionais - já formados e inseridos num modelo fragmentado assumir a responsabilidade pela formação de novos profissionais (com perfil diferente) sobretudo se considerarmos a colocação dos discentes em serviços, cuja tendência é a crescente fragmentação das atividades e rotatividade de profissionais devido à privatização e flexibilização.

Realizamos uma pesquisa ${ }^{11}$ no Instituto de Atenção à Saúde, que pertence à Universidade Federal do Rio de Janeiro (Hesfa/UFRJ) e possui programa de residência em Saúde. Constatamos que ainda há prevalência de uma concepção abstrata sobre saúde e falta de participação dos preceptores nos espaços coletivos e políticos do SUS. Essa falta de participação pode ser parte e expressão da não apreensão do significado da concepção ampliada e política de Saúde do Movimento de Reforma Sanitária, apesar da alta qualificação dos preceptores (especialistas, sendo alguns já mestres), vinculados a serviços de referência a maioria em uma universidade federal e mais de três anos envolvidos na formação de um curso de Residência Multiprofissional. A pesquisa sugere, também, a falta de participação mais efetiva dos preceptores na construção e discussão do Projeto Político-Pedagógico do curso.Aorganização do trabalho realizado se distancia do molde multiprofissional e há, ainda, a inexistência e fragmentação do planejamento multiprofissional das atividades de ensino (SILVA, 2015).

Dentro desse contexto das RMSsurge uma questão: quais os dilemas impostos ao trabalho dos assistentes sociais nestes espaços para a formação crítica de residentes de diferentes áreas profissionais?

\section{O assistente social nas Residências Multiprofissionais em Saúde: Projeto Ético-Político do Serviço Social, formação e trabalho profissional}

Segundo Netto (2006), as ações humanas sempre são orientadas por objetivos, com fins e metas, isto é, são ações projetadas. Os projetos coletivos são projetos societários que, em sociedades como a nossa, são

\footnotetext{
${ }^{11 E s t u d o ~ r e a l i z a d o ~ p a r a ~ o ~ T r a b a l h o ~ d e ~ C o n c l u s a ̃ o ~ d a ~ R e s i d e ̂ n c i a M u l t i p r o f i s s i o n a l ~ e m ~ S a u ́ d e ~ d a ~ M u l h e r ~ d o ~ I n s t i t u t o ~ S a ̃ o ~}$ Francisco de Assis (Hesfa), Universidade Federal do Rio de Janeiro (UFRJ). A metodologia do estudo foi pesquisa qualitativa e realizou-se a partir dos relatos de 12 preceptores que pertencem às seguintes áreas de conhecimento: Serviço Social, Psicologia e Enfermagem.
} 


\section{ReVista ell pautg}

\} RESIDÊNCIA MULTIPROFISSIONAL EM SAÚDE - SILVA, L. C.; BROTTO, M. E. \}

DOI: $10.12957 /$ REP.2016.25396

necessariamente projetos de classe, respondendo a interesses da classe trabalhadora ou da classe capitalista. O Projeto Ético Político do Serviço Social brasileiro está vinculado a um projeto de superação da sociedade capitalista. Tendo em vista que a prática do assistente social atua no movimento contraditório das classes, das ações mais simples até às mais complexas, imprime uma direção social ético-política, teórico-metodológica e técnico-operativa específica.

No marco dos projetos coletivos, inscrevem-se os projetos profissionais que apresentarão a autoimagem da profissão contendo dimensões políticas. Ademais, o projeto profissional é construído pela organização do conjunto dos membros que dão efetividade à profissão. A condição para a construção do atual projeto do Serviço Social no Brasil remonta aos anos de 1970 e 1980, com a reinserção da classe trabalhadora na cena política, a resistência à Ditadura e mobilizações por demandas democráticas e populares que estavam reprimidas. Dessa forma, o conservadorismo do Serviço Social se viu confrontado e contestado pela sociedade e pela mobilização da vanguarda existente no corpo profissional que, vinculada aos movimentos dos trabalhadores, ativou-se politicamente. Visava, assim, à construção de um novo perfil da categoria profissional, em consonância com a exigência intelectual do projeto progressista.

Atualmente, reafirma-se a necessidade de que o Projeto Ético Político Profissional se fortaleça como hegemônico na profissão, mas observa-se que este encontra dificuldades de se fazer e se consolidar na realidade profissional devido aos rebatimentos do neoliberalismo na realidade profissional dos assistentes sociais. Os profissionais dentro da atual conjuntura (da ordem econômica capitalista/neoliberal: de estímulo ao individualismo, à competitividade, alocação de recursos públicos para interesses privados, entre outros) têm, na sua ação, limites e possibilidades nas instituições em que estão inseridos.

Alguns autores do Serviço Social brasileiro discutem esse clássico dilema. Considera-se que tão importante quanto apreender as profissões no contexto da contraditória sociedade do capital é deixar claro que é na própria contradição de interesses entre capital/trabalho que está a possibilidade de uma prática social (a prática dos profissionais, como sua parte e expressão) fortaleça os interesses da saúde da população (VASCONCELOS, 2009).

Nos termos de lamamoto (2008a), teleologia e causalidade advêm da seguinte problemática: o exercício profissional realiza-se pela mediação do trabalho assalariado, que tem no Estado, e nos organismos privados, suas bases de sustentação. Verifica-se um embate entre o exercício profissional, controlado pelos empregadores, as necessidades dos usuários e a autonomia do profissional. Com isso, podemos dizer que é neste cenário conflituoso que a prática na Saúde ganha materialidade. Prática esta sujeita a determinações históricas que fogem ao controle dos profissionais e impõem 


\section{ADVistg all paUtg}

\} RESIDÊNCIA MULTIPROFISSIONAL EM SAÚDE - SILVA, L. C.; BROTTO, M. E. \}

DOI: $10.12957 /$ REP.2016.25396

limites, com momentos de possibilidades de ações planejadas na defesa de um projeto alternativode prática social (teleologia). Neste sentido, para que o profissional tenha condições de perceber as possibilidades existentes na realidade, necessita de uma formação que lhe dê condições de conhecer o real para além dos seus limites.

Ainda segundo lamamoto (2008a), a condição de venda e compra da força de trabalho restringe, em graus variados, a autonomia profissional na direção social desse exercício, com incidências na sua configuração técnico-profissional. Assim, as exigências impostas pelos distintos empregadores também incidem nas requisições feitas ao profissional e estabelecem limites e possibilidades à realização dos propósitos profissionais.

Dessa forma, estamos diante de uma realidade na qual, se a educação na área da Saúde não puder formar profissionais críticos, com certeza os campos do trabalho e da formação ser cada vez mais apropriados pelos interesses do capital, sem a resistência teórica e política dos trabalhadores.Visando contribuir para a superação da ordem vigente, os profissionais dessa área têm um papel fundamental:criar estratégias e contribuir no fortalecimento deste projeto no trabalho profissional.

A inserção dos assistentes sociais na Academia, mesmo com as contradições vivenciadas pela Ditadura Militar no Brasil, vem possibilitando um processo de investigação através da articulação entre pesquisa, ensino e extensão. Porém, Netto (2011) afirma que, no meio profissional, sua expressão é limitada no que se refere à incidência prático-operacional. $\mathrm{O}$ autor observa que há poucos indicativos prático-operativos para a concretização deste projeto no cotidiano do exercício da profissão, destacando que o processo de ruptura com o conservadorismo se espraia na Academia e nas produções, expressando-se nos principais congressos e seminários da categoria, que necessitam de proposições não prescritivas para o exercício profissional.

O atual Projeto Ético Político do Serviço Social se mostra hegemônico enquanto organização nas entidades de representação da categoria e na legislação. Contudo, encontra problemas e desafios quanto à materialização em relação à formação e à prática. As políticas econômicas e sociais, impostas pela realidade neoliberal do capitalismo, refletem-se diretamente no cotidiano de trabalho dos assistentes sociais, seja nas unidades de formação, seja nos espaços sócio-ocupacionais.

Segundo lamamoto (2008b), a investigação é uma atividade fundamental para subsidiar a construção de alternativas críticas para enfrentar a questão social. Assim, a investigação, segundo a autora, é central na formação e na qualificação do exercício profissional. Ao identificar o quadro temático dos rumos da pesquisa no Serviço Social e seus desdobramentos, a partir dos resultados da Avaliação Trienal dos programas de Pós-Graduação da Capes/MEC (2001-2003), a autora sinaliza que a agenda temática da pesquisa em Serviço Social não tem privilegiado a investigação do trabalho e a prática profissional. 


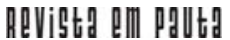

\} RESIDÊNCIA MULTIPROFISSIONAL EM SAÚDE - SILVA, L. C.; BROTTO, M. E.\}

DOI: $10.12957 /$ REP.2016.25396

lamamoto (2008b) salienta, ainda, que a produção de conhecimento do Serviço Social, no seu conjunto, ultrapassou a visão endógena da profissão, através da apropriação teórico-metodológica de grandes matrizes do pensamento social na modernidade, mas que essas conquistas ainda não foram efetivadas integralmente no exercício profissional, faltando fazer "a viagem de volta para apreender o trabalho profissional nas suas múltiplas determinações e relações no cenário atual" (IAMAMOTO, 2008, p. 463). Tal estudo destaca a necessidade da categoria priorizar a reflexão sobre o exercício profissional nas diversas áreas de atuação. Para a autora, é indispensável particularizar a análise do exercício profissional ou a pesquisa de situações concretas. Além disso, destaca a urgência da discussão e relação do exercício profissional com as competências profissionais e atribuições privativas do assistente social.

Em consonância com lamamoto (2008b), também temos Vasconcelos (2009), que ressalta o grave momento por que vem passando o exercício profissional dos assistentes sociais, ou seja, a "fratura entreprática do Serviço Social e as possibilidades de práticas emancipatórias, contidas na realidade objeto da ação profissional" (VASCONCELOS, 2009). Diante do acúmulo que a profissão começou a vivenciar desde o Movimento de Reconceituação (NETTO, 2011), o desafio para os assistentes sociais que buscam um exercício profissional rompido com o conservadorismo nos espaços de prática é a apropriação de uma perspectiva teórico-metodológica e éticopolítica que, colocando referências concretas para a ação profissional, possa gerar condições para um exercício profissional consciente, crítico, criativo e politizante que, segundo a autora, só é possível na unidade entre teoria e prática.

Diante da exposição relacionada à direção ético-política e teóricometodológica assumida pelo Serviço Social nos últimos tempos, temos a pressuposição de que o assistente social, ao inserir-se na residência em Saúde, tem grande potencial de contribuição crítica, dada a sua particularidade profissional. No entanto, dentro do contexto avesso às intenções democratizantes na Saúde, os assistentes sociais possuem como desafio a dificuldade de planejar, imprimir ações e identificar possibilidades de práticas condizentes com a sua intenção crítica. Isso ocorre devido à tensão própria do seu assalariamento, que reflete relativa autonomia dentro de um contexto de precarização das políticas públicas e do trabalho.

Uma pesquisa de Ceccim e Dallegrave (2013) buscou analisar 94 estudos de teses e dissertações sobre residências em Saúde produzidas no Brasil no período entre 1987 e 2011, a partir do banco de teses do portal Capes. O estudo nos apresenta um panorama sobre a temática das residências, que tem aumentado nos últimos anos, demonstrando a importância da educação pelo trabalho como metodologia potente para formar trabalhadores da Saúde. Em seu conteúdo, os autores identificaram somente duas produções no período referido que discutem a inserção de assistentes

EM PAUTA, Rio de Janeiro - 1 $^{\circ}$ Semestre de 2016 - n. 37, v. 14, p. 126 - 149 


\section{ADVistg all paUtg}

\} RESIDÊNCIA MULTIPROFISSIONAL EM SAÚDE - SILVA, L. C.; BROTTO, M. E.

DOI: $10.12957 /$ REP.2016.25396

sociais em Residências Multiprofissionais: dissertações de Vargas (2011) e Closs (2010).

O estudo de Vargas (2011) discute as particularidades do Serviço Social no contexto dos Programas de Residência Multiprofissional em Saúde, em Porto Alegre, nos anos de 2009 e 2010. O objetivo é analisar as expressões das particularidades do Serviço Social nos programas de RMS, a fim de identificar sua inserção no cotidiano da Educação Permanente em Saúde. Constatou-se, na inserção do assistente social, possibilidades para a consolidação do Projeto Ético Político Profissional, também direcionado ao enfrentamento do projeto societário hegemônico. Para isso, todavia, seria fundamental ampliar a reflexão em relação às atividades desenvolvidasno espaço de trabalho, articuladas ao referencial crítico-dialético.

Segundo a autora, no desenvolvimento das atividades, a competência para um olhar ampliado e diferenciado em relação às situações apresentadas legitima o Serviço Social no contexto da residência. O fato de a maioria dos profissionais entrevistados reafirmarem o compromisso com os direitos e interesses dos usuários evidencia a contraposição em relação à herança conservadora da profissão, contudo, ressalta que essas implicações precisam ser aprofundadas no planejamento das ações, articuladas com os movimentos sociais e os espaços de controle social, para o atendimento a essas demandas.

O estudo de Closs (2010) objetivou analisar a inserção do Serviço Social na Residência Multiprofissional em Saúde na Atenção Básica, identificando as contribuições do Serviço Social para a construção da integralidade e as repercussões da residência nessa profissão. Constatou-se que a maioria dos assistentes sociais relaciona a integralidade com o conceito ampliado de saúde, destacando a visão de totalidade na apreensão da necessidade da população usuária. Quanto às contribuições da profissão para integralidade, foram referidos dois eixos principais: os aportes da particularidade do Serviço Social nas equipes - tais como a "visão" crítica e totalizante da saúde e a direção social do Projeto Ético-Político Profissional e o enfoque para o protagonismo do usuário.

Os referidos estudostêm em comum a constatação, já apontada por Vasconcelos (2010), do potencial do Serviço Social em relação à competência crítica, relacionado com a sua formação generalista e forte tendência à intenção de fortalecer o atual projeto da profissão.

lamamoto (2002) é clara ao defender que a identidade das equipes profissionais, em torno de competências comuns, não exclui as particularidades profissionais. Para ela, o assistente social, mesmo partilhando o trabalho com os outros profissionais, dispõe de singularidades na interpretação dos mesmos processos sociais, assim como uma competência distinta para a realização das ações profissionais. Esta competência decorre de vários fatores, dentre eles,formação profissional, a capacitação teórico-metodológica e competência na habilidade para desenvolver determinadas ações. 


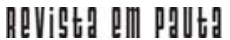

\} RESIDÊNCIA MULTIPROFISSIONAL EM SAÚDE - SILVA, L. C.; BROTTO, M. E. \}

DOI: $10.12957 /$ REP.2016.25396

Dessa forma, um projeto profissional crítico vai além da defesa de determinados valores, pois implica a existência de um corpo de conhecimentos que sustente a definição e a execução das ações profissionais. No que se refere ao Projeto Ético Político do Serviço Social brasileiro, é importante recordarque este contempla, tanto no âmbito da formação como no do exercício profissional, a indissociabilidade das dimensões teórico-metodológica, ético-política e técnico-operativa.

Nesse sentido, consideramos que a aproximação da realidade da inserção do assistente social na Residência Multiprofissional (um programa em recente expansão dentro da Política de Recursos Humanos no SUS) consiste em dar vOz aos aspectos do cotidiano profissional, com as suas possibilidades e limites dentro da contraditória sociabilidade capitalista. Da mesma forma, requer interação entre teoria e prática, tendo em vista que a supervisão profissional se relaciona com a dimensão pedagógica do exercício profissional, articulando formação e trabalho.

É válido ressaltar que, historicamente, os assistentes sociais dedicaram-se à implementação de políticas públicas, localizando-se na linha de frente das relações entre população/instituições ou, nos termos de Netto (1992), sendo "executores terminais de políticas sociais". Embora esse seja ainda o perfil predominante, não é mais exclusivo, visto que está aberto a outras possibilidades.

O processo de descentralização das políticas sociais públicas, com ênfase na sua municipalização, requer dos assistentes sociais - como de outros profissionais - novas funções e competências. Os assistentes sociais estão sendo chamados a atuar na esfera da formação de outros profissionais inscritos em equipes multiprofissionais. Dessa forma, ampliam seu espaço ocupacional, em que tais inserções são acompanhadas de novas exigências de qualificação.

A inserção do assistente social através da preceptoria nas RMS se relaciona diretamente com a dimensão educativa do trabalho profissional - a da supervisão profissional. As autoras Guerra e Braga(2009), ao discutirem a supervisão no Serviço Social, afirmam que este é um tema que ainda se encontra muito ausente em debates e produções bibliográficas da profissão, sendo que a supervisão mostra sua relevância ao propiciar qualificação, direcionando aos objetivos do Projeto ÉticoPolítico da profissão. Desse modo, a supervisão representa a estreita relação entre trabalho e formação, teoria e prática profissional e, em qualquer que seja a modalidade, deve estar comprometido com a qualidade, visando ao aprimoramento pautado no projeto profissional.

Ao sintetizar a teoria e a prática com respaldo teórico, a supervisão passa a fazer parte do processo de construção de possibilidades e de "alternativas e respostas profissionais" (GUERRA; BRAGA, 2009, p.534). A supervisão (em qualquer modalidade) depara-se com as "contradições da realidade social" e com uma variedade de interesses e demandas, podendo 


\section{ApVistg all paUtg}

\} RESIDÊNCIA MULTIPROFISSIONAL EM SAÚDE - SILVA, L. C.; BROTTO, M. E.

DOI: $10.12957 /$ REP.2016.25396

apresentar tanto uma ação reguladora, quanto emancipatória, pois possui capacidade crítico- reflexiva.

Pode-se observar, portanto, que a atividade profissional se inscreve com predominância no terreno político e ideológico, com reflexos nas condições materiais da existência dos sujeitos via serviços, programas e projetos implementados pelas políticas públicas, que interferem no padrão de consumo e na qualidade de vida das famílias trabalhadoras.

\section{Considerações finais}

Diante do enfrentamento de uma política de contrarreformas, a afirmação de um projeto profissional e político-pedagógico voltado para uma formação crítica, reflexiva, teórico-metodológica, técnico-operativa e ético-política é de extrema importância para a formação dos profissionais e fortalecimento do SUS.

Em um cenário avesso ao SUS universal e de qualidade,capaz de resistir aos ditames do capital, considera-se de suma importância que se formem profissionais/intelectuais críticos e consonantes com os princípios e diretrizes do SUS - para que a relativa autonomia reservada aos profissionais de nível superior possa ser aproveitada a favor da luta pela Saúde coletiva.

No que se refere ao projeto de Saúde e ao projeto profissional do Serviço Social, Mioto e Nogueira(2006) fizeram um estudo comparando os princípios convergentes do projeto da Reforma Sanitária para a Saúde e o atual Projeto Ético Político hegemônico no Serviço Social. Segundo as autoras, a convergência das propostas inspirou a letra constitucional para a Saúde com o Código de Ética Profissional e a Lei da Regulamentação da Profissão, aprovados em 1993.

Porém, a reversão posta em prática, a partir da década de 1990, nas propostas fundamentais da Seguridade Social brasileira, quebrou as expectativas de parte da sociedade com relação à ampliação de direitos sociais. Em consequência disso, podemos observar que os dois projetos políticos em disputa na área da Saúde projeto privatista e o projeto da Reforma Sanitária - apresentaram diferentes requisições práticas para o trabalho em Saúde, em especial para o Serviço Social. O projeto privatista requisitou, e vem requisitando, uma postura assistencialista, através da ideologia do favor e do predomínio de práticas individuais. Entretanto, o projeto da Reforma Sanitária apresenta como demandas a busca pela democratização do acesso às unidades e aos serviços de Saúde, do atendimento humanizado e de estímulo à participação cidadã (BRAVO, 1998).

São requisições contraditórias que se apresentam nas realidades profissionais. Por isso, para o profissional que pretende dar tom àsua ação pelo viés crítico, criar estratégias para fortalecer a herança sanitária do 


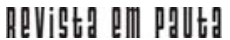

\} RESIDÊNCIA MULTIPROFISSIONAL EM SAÚDE - SILVA, L. C.; BROTTO, M. E.\}

DOI: $10.12957 /$ REP.2016.25396

SUS, bem como formular propostas que trazem consigo possibilidades de um trabalho consonante com o projeto profissional do Serviço Social, tornam-se um desafio. Por esse motivo (diante das propostas de implementação das residências em Saúde e seu discurso de fortalecimento dos princípios do SUS, em uma realidade que contraditoriamente o precariza), entendemos como é desafiador para os assistentes sociais mediar um trabalho voltado à direção do SUS e do projeto profissional. Tal mediação pode contribuir na formação de um perfil profissional, de acordo com o projeto da Reforma Sanitária para a Saúde pública brasileira.

Não podemos esquecer da importância e do protagonismo que os sujeitos que atuam "na ponta" (trabalhando e ensinando) têm na consolidação do SUS, sendo conveniente salientar que grande parte dos defensores do movimento da Reforma Sanitária eram profissionais, pesquisadores, docentes e estudantes vinculados aos serviços de Saúde.

Os modelos de atenção e formação em Saúde são quase impossíveis de serem discutidos separadamente e, ainda que se avalie como de imprescindível importância a discussão em torno da formação de profissionais para o SUS, consideramos essencial buscar meios de garantir que o modelo de atenção e o trabalho no SUS atendam aos desafios que estão sendo colocados para a implementação do sistema e da qualificação profissional.

Neste sentido, é preciso destacar que, enquanto a lógica mercantil - nesses moldes atuais de parasita do SUS - não for enfrentada de forma estrutural, o caminho de fortalecimento do SUS será mais dificultoso.Ressaltamos, ainda, que o enfrentamento de forma estrutural deve ser feito: com o fim do subfinanciamento do nosso sistema de Saúde público; na disputa pelo perfil de formação dos trabalhadores da Saúde; na regulação das especialidades e residências de acordo com as necessidades de Saúde da população, e não do mercado; na criação de estratégias de absorção desses profissionais pelo SUS público, e não pela rede privada ou pública terceirizada.

Cabe lembrar que o movimento sanitário entendia que o modelo de assistência à Saúde, implementado no Brasil durante a Ditadura Militar - curativo, individual, assistencialista, médico-centrado, hospitalocêntrico, superespecializado, orientado para o lucro e favorecimento do complexo médico-industrial -, era altamente excludente, financeiramente insustentável e incapaz de dar resposta às necessidades de saúde da população. Então, como alternativa, propunha-se a reorientação desse modelo assistencial através da criação de um Sistema Único de Saúde estatal, orientado pela atenção básica e guiado por princípios como a universalidade, integralidade e equidade. Defendê-lo e aprimorá-lo é uma luta fundamental e constante. 


\section{ApVistg all paUtg}

\} RESIDÊNCIA MULTIPROFISSIONAL EM SAÚDE - SILVA, L. C.; BROTTO, M. E. \}

DOI: $10.12957 /$ REP.2016.25396

\section{Referências}

AGUIAR, A.M.T;BALTAR, J.F;COELHO, V.H.S; LIMA, R.C.M; MIRANDA, M. C; SILVA, C.S; SILVA, J.F; SOUZA, M.S; VASCONCELOS, A.M. Profissões de saúde, diretrizes curriculares e sistema único de saúde brasileiro (sus). In: XI Encontro Nacional de Pesquisadores em Serviço Social, 2008, São Luiz/MA. XI Encontro Nacional de Pesquisadores em Serviço Social. São Luiz/MA: ABEPSS, 2008.

BEHRING, E. R.; BOSCHETTI, I.Política social: fundamentos e história. São Paulo:Ed Cortez. 2006.

BRASIL. Resolução 287 de 08 de outubro de 1998. Ministério da Saúde. Brasília. 1998.

.Política de educação e desenvolvimento para o SUS: caminhos para a educação permanente e pólos de educação permanente em saúde. Ministério da Saúde. Brasília, 2004.

- A educação permanente entra na roda: educação permanente em saúde:conceitos e caminhos a percorrer. Ministério da saúde. Brasília, 2005 BRASIL. Princípios e Diretrizes para a Gestão do Trabalho no SUS. Norma operacional básica de Recursos Humanos do SUS (NOB/RH-SUS). Ministério da Saúde. Brasília. 2005.

- Residência multiprofissional em saúde: experiências, avanços e desafios / Ministério da Saúde, Secretaria de Gestão do Trabalho e da Educação na Saúde, Departamento de Gestão da Educação em Saúde. - Brasília: Ministério da Saúde, 2006.

- Relatório de Atividades da Comissão Nacional de Residência Multiprofissional em Saúde - CNRMS - Exercício 2007/2009. Ministério da Educação, Ministério da Saúde. Brasília, 2009.

. Diretrizes Gerais para os Programas de Residência Multiprofissional e em Profissional de Saúde. Ministério da Educação. Brasília. RESOLUÇÃO n. 2, DE 13 DE ABRIL DE 2012.

BRAVO, M. I. S. Serviço Social na Saúde na década de 90. Superando Desafios. Cadernos do Serviço Social do Hupe. Rio de Janeiro: Uerj, 1998.

- Saúde e Serviço Social. Cortez:Rio de Janeiro. 2006.

. Política de Saúde no Brasil. Serviço Social e Saúde, Formação e Trabalho Profissional. São Paulo: Editora Cortez, 2009.

. et al. (Org.). Cadernos de saúde: a mercantilização da saúde em debate. Rio de Janeiro: Rede Sirius, 2015.

CECCIM, R. B.; FERLA, A. A. Notas cartográficas sobre a escuta e a escrita: contribuição à educação das práticas de saúde. In: PINHEIRO, R.; MATTOS, 


\section{ReVista ell pautg}

\} RESIDÊNNCIA MULTIPROFISSIONAL EM SAÚDE - SILVA, L. C.; BROTTO, M. E. \}

DOI: $10.12957 /$ REP.2016.25396

R. A. (Org.) Construção social da demanda: direito à saúde, trabalho em equipe, participação e espaços públicos. Rio de Janeiro: Uerj/IMS/Cepesc/ Abrasco.2005.

.Educação e saúde: ensino e cidadania como travessia de fronteiras.Trab. Educ. Saúde, v.6 n.3,nov.2008/fev.2009.Disponível em: $<$ http://www.revista.epsjv.fiocruz.br/upload/revistas/r219.pdf>. Acesso em: 15 set. 2014.

CECCIM, R. B.; FEUERWERKER, L. C. M. O quadrilátero da formação para a área da Saúde: ensino, gestão, atenção e controle social. PHYSIS: Revista de Saúde Coletiva, Rio de Janeiro 2004.

CECCIM, R. B.; DALLEGRAVE, D. Residências em saúde: o que há nas produções de teses e dissertações? Interface, Botucatu, v. 17, p. 759-776. 2013.

CISLAGHI, J. F. Retrocessos no legislativo e impactos para a saúde no Brasil. In: BRAVO, M.I.et al. (Org). Cadernos de saúde: a mercantilização da saúde em debate. Rio de Janeiro: Rede Sirius.2015b.

CLOSS, T. T. O Serviço Social nas Residências Multiprofissionais em Saúde na Atenção Básica: formação para a integralidade? Dissertação (Mestrado) -Programa de Pós- Graduação em Serviço Social, Pontifícia Universidade Católica do Rio Grande do Sul, Porto Alegre.2010.

GUERRA, Y.; BRAGA, M. E. Supervisão em Serviço Social. In: CFESS (Org.).Serviço Social: direitos sociais e competências profissionais. Brasília: CFESS/Abepss. 2009.

IAMAMOTO, M. V. Projeto profissional, espaços ocupacionais e trabalho do assistente social na atualidade.In: CFESS. Atribuições privativas do(a) assistente social. Brasília:CFESS2002.

. O Serviço Social na contemporaneidade: trabalho e formação profissional. São Paulo :Cortez.2008a.

- Serviço Social em tempo de capital fetiche: capital financeiro, trabalho e questão social.São Paulo: Cortez.2008b.

LOBATO, C. P. Formação dos trabalhadores de saúde na residência multiprofissional em saúde da família:uma cartografia da dimensão política. 2010. Tese (Doutorado em SaúdeColetiva) Universidade Estadual de Londrina, Londrina. 2010.

MENDES, E. V. 25 anos do Sistema Único de Saúde: resultados e desafios.Estudos Avançados, v. 27, n. 782013.

MIOTO, R.C.T; NOGUEIRA, V. M. R. Desafios atuais do Sistema Único de Saúde (SUS) e as exigências para os assistentes sociais. In: MOTA, A. E; et al. (Org.). Serviço Social e saúde. Formação e trabalho profissional. São Paulo: Cortez, 2006. 


\section{ReVistg all pavtg}

\} RESIDÊNCIA MULTIPROFISSIONAL EM SAÚDE - SILVA, L. C.; BROTTO, M. E.

DOI: $10.12957 /$ REP.2016.25396

NETTO, J.P. Capitalismo monopolista e Serviço Social. São Paulo:Cortez.1992.

A construção do Projeto Ético-Político do Serviço Social. Serviço Social e Saúde: Formação e trabalho profissional. São Paulo: Cortez, 2006.

. Ditadura e Serviço Social. Uma análise do Serviço Social no Brasil pós-64. São Paulo. Cortez. 2011.

RAMOS, A. S. et al. Introdução: a trajetória da residência multiprofissional em Saúde no Brasil. In:Residência Multiprofissional em Saúde: experiências, avanços e desafios. Brasília: Ministério da Saúde,2006. Disponível em: <http://bvsms.saude.gov.br/bvs/publicacoes/residencia_multipro fissional.pdf>. Acesso em: 15 fev. 2006.

SANTOS, J. S. "Questão social": particularidades no Brasil. Biblioteca Básica de Serviço Social, v. 6. 2012.

SILVA, L. C. Formação e prática na saúde: o processo ensino-aprendizagem na Residência Multiprofissional em Saúde da Mulher a partir do relato dos preceptores.Trabalho de Conclusão de Curso (Especialização Residência Multiprofissional em Saúde da Mulher) Hesfa/UFRJ. Rio de Janeiro. 2015. Mimeo.

VARGAS, T. M. O Serviço Social no programa de residência multiprofissional em saúde: uma estratégia de consolidação do projeto ético-político profissional? 2011. Dissertação (Mestrado) - Faculdade de Serviço Social, Pontifícia Universidade Católicado Rio Grande do Sul, Porto Alegre. 2011.

VASCONCELOS, A. M. A prática do Serviço Social: cotidiano e práticas democráticas. Projeto de Pesquisa/Extensão. Rio de Janeiro: CNPq/Faperj/ FSS-Uerj. 2009.

A prática dos profissionais de saúde no município do Rio de Janeiro. Hospitais Universitários. Projeto de Pesquisa. Rio de Janeiro: CNPq/Faperj/ FSS-Uerj. 2010.

Recebido em 30 de abril de 2016.

Aprovado para publicação em 27 de junho de 2016.

DOI: $10.12957 /$ rep.2016.25396

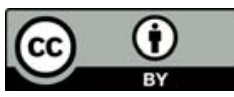

A Revista Em Pauta: Teoria Social e Realidade Contemporânea está licenciada com uma Licença Creative Commons Atribuição 4.0 Internacional. 